\title{
Effect of deformation temperature on the structural parameters, phase composition and microhardness of Fe-28Mn-2.7Al-1.3C steel single crystals processed by high-pressure torsion
}

\author{
E. V. Melnikov ${ }^{\dagger}$ E. G. Astafurova, G. G. Maier \\ ${ }^{\dagger}$ melnickow-jenya@yandex.ru
}

Institute of Strength Physics and Materials Science SB RAS, 2/4 pr. Akademicheskii, Tomsk, 634055, Russia

Using X-ray diffraction method, the effect of cold $\left(23^{\circ} \mathrm{C}\right)$ and warm $\left(200,400^{\circ} \mathrm{C}\right)$ high-pressure torsion $(\mathrm{HPT}, 6 \mathrm{GPa}, \mathrm{N}=1$, 3, 5 full revolutions) on the structural parameters and phase composition of single crystals of high-manganese austenitic steel Fe-28Mn-2.7Al-1.3C (wt. \%) was investigated. HPT leads to the formation of a misoriented austenitic structure with predominant orientation of $\{111\}$-planes in the plane of the anvils. Increase in strain (the number of revolutions) contributes to a decrease in sizes of the coherent scattering regions and microstrain of the crystal lattice and causes an increase in the concentration of stacking faults calculated on the basis of the strain-induced shifting of X-ray lines. Regardless of the deformation temperature and the number of revolutions under HPT, steel retains an austenitic structure with lattice parameter of 3.638-3.653 $\AA$. An increase in deformation temperature contributes to a decrease in the austenite crystal lattice parameter that indicates on a partial decarburization of austenite, but only austenite lines are observed on X-ray diffraction patterns. As a result of deformation, the microhardness of the steel increases, and its magnitude significantly depends on the HPT temperature. In the case of cold deformation by HPT, the distribution of microhardness along the diameter of the disk is quasi-homogeneous and varies slightly with increasing number of revolutions. An increase in the deformation temperature is accompanied by the appearance of inhomogeneity in the distribution of the microhardness along the diameter of the disk the values at the center are lower than that at the periphery.

Keywords: single crystals, steel, high-pressure torsion, microhardness, twinning.

УДК: 669.14:539.4

\section{Влияние температуры деформации на параметры структуры, фазовый состав и микротвердость монокристаллов стали Fe-28Mn-2.7 Al-1.3C, подвергнутых кручению под высоким давлением}

\author{
Мельников Е. В. ${ }^{\dagger}$, Астафурова Е. Г., Майер Г. Г.
}

Институт физики прочности и материаловедения СО РАН, пр. Академический, 2/4, Томск, 634055, Россия

\begin{abstract}
Методом рентгеновской дифракции изучали влияние холодного (при $T=23^{\circ} \mathrm{C}$ ) и теплого (при $T=200$ и $\left.400^{\circ} \mathrm{C}\right)$ кручения под высоким давлением (6 ГПа, $N=1,3$ и 5 полных оборотов) на параметры структуры и фазовый состав монокристаллов высокомарганцевой аустенитной стали Fe-28Mn-2,7Al-1,3C (вес. \%). Кручение под давлением приводит к формированию разориентированной аустенитной структуры с преимущественной ориентацией плоскостей $\{111\}$ в плоскости наковален. Увеличение степени деформации (числа оборотов при кручении под давлением) способствует уменьшению размеров областей когерентного рассеяния и микродеформации кристаллической решетки и вызывает рост концентрации дефектов упаковки, рассчитанной на основе данных о смещении рентгеновских линий при деформации. Независимо от температуры и числа оборотов, при кручении под давлением сталь сохраняет аустенитную структуру с параметром решетки 3.638 - $3.653 \AA$ А. Увеличение температуры деформации способствует снижению параметра кристаллической решетки аустенита, что свидетельствует о частичном обезуглероживании аусте-
\end{abstract}


нита, но на рентгенограммах наблюдаются только линии аустенита. В результате деформации микротвердость стали увеличивается, и ее величина существенным образом зависит от температуры кручения. Самые высокие значения микротвердости, микродеформации кристаллической решетки и концентрации дефектов упаковки соответствуют деформации при $T=200^{\circ} \mathrm{C}$. При холодной деформации кручением под высоким давлением распределение микротвердости по диаметру диска является квазиоднородным и слабо изменяется с ростом числа оборотов. Увеличение температуры деформации ведет к неоднородному распределению микротвердости по диаметру диска - в центре значения ниже, чем на периферии.

Ключевые слова: монокристаллы, сталь, кручение под высоким давлением, микротвердость, двойникование.

\section{1. Введение}

В последние годы для измельчения микроструктуры металлов, сплавов и композиционных материалов широкое применение получили методы, основанные на интенсивной пластической деформации, которые приводят к измельчению элементов структуры до наноструктурного уровня и способствуют значительному улучшению прочностных свойств обрабатываемых материалов [1 -3]. Среди многочисленных методов интенсивной пластической деформации, кручение в наковальнях Бриджмена (или кручение под высоким давлением, КВД) является особенно привлекательным, поскольку позволяет достичь экстремально больших степеней деформации без разрушения заготовки [1-3]. На сегодняшний день метод КВД использован для обработки множества металлических материалов. Вместе с тем, по отношению к высокопрочным сталям с высокой концентрацией атомов внедрения этот метод применялся очень мало [4-10]. Тем не менее, уже проведенные исследования показали, что измельчение микроструктуры в высокопрочных сталях дает значительный вклад в упрочнение материала, дополнительный к твердорастворному, дисперсионному, субструктурному упрочнению [4-10]. Подход, связанный с воздействием большой пластической деформации на структуру металлических материалов, может быть перспективным в управлении микроструктурой высокомарганцевых аустенитных TWIP-сталей. Они имеют исключительную комбинацию высокой прочности и превосходной пластичности благодаря их способности к деформационному упрочнению и склонности к развитию механического двойникования при деформации [11]. Немногочисленные экспериментальные работы, выполненные на моно- и поликристаллах TWIP-сталей, подвергнутых КВД, свидетельствуют о важной роли этого механизма деформации в измельчении структуры и формировании прочностных свойств [5, 6, 7, 12 - 13].

Использование монокристаллов, как объектов исследования, позволяет избежать вклада в упрочнение и фрагментацию структуры от исходных границ зерен и изучить механизмы деформации сталей в чистом виде. Так, в работах $[5,6]$ с использованием монокристаллов высокомарганцевых сталей Fe-13Mn-1.3C, Fe-13Mn-2,7Al-1,3C и Fe-28Mn-2,7Al-1,3C, деформированных методом КВД, было установлено, что механическое двойникование, являющееся высокотемпературным механизмом деформации, вызывает сильные эффекты упрочнения и развивается даже в сталях с высокой энергией дефекта упаковки, в которых оно обычно не наблюдается при деформации одноосным растяжением или сжатием.

Целью настоящего исследования является изучение влияния температуры деформации в наковальнях Бриджмена на параметры структуры, фазовый состав и микротвердость монокристаллов высокомарганцевой аустенитной стали Fe-28Mn-2.7Al-1.3C.

\section{2. Материалы и методы исследования}

Монокристаллы аустенитной высокомарганцевой стали Fe-28Mn-2.7Al-1.3C (мас. \%) были выращены методом Бриджмена в среде инертного газа. Затем кристаллы были гомогенизированы в среде аргона при $T=1100-1150^{\circ} \mathrm{C}$ в течение 24 часов. Для получения аустенитной структуры заготовки закаливали после часовой выдержки в среде гелия при $T=1100^{\circ} \mathrm{C}$.

Образцы вырезали в форме дисков диаметром 10 мм и толщиной 0,6 мм, оси дисков совпадали с кристаллографическим направлением $<111>$ монокристаллов. Поврежденный при резке слой удаляли механическим шлифованием и электролитической полировкой (в растворе 25 г $\mathrm{CrO}_{3}+210$ мл $\mathrm{H}_{3} \mathrm{PO}_{4}$ при комнатной температуре). Деформацию образцов кручением под высоким давлением (КВД) проводили на наковальнях Бриджмена под давлением $P=6$ ГПа и температурах $T=23^{\circ} \mathrm{C}\left(T / T_{\text {пл }} \approx 0,1, \mathrm{KBД}_{23}\right)$, $200^{\circ} \mathrm{C}\left(T / T_{\text {пл }} \approx 0,15 \mathrm{KBД}_{200}\right), 400^{\circ} \mathrm{C}\left(T / T_{\text {пл }} \approx 0,3\right.$, КВД $\left._{400}\right)$ на $N=1,3$ и 5 полных оборотов. До температуры деформации диски нагревали в течение 10 минут. Скорость вращения пуансонов составляла 1 об/мин. После деформации образцы снимали с пуансонов и остужали на воздухе. Поверхностный слой образцов удаляли механическим шлифованием и электролитической полировкой. Структуру и микротвердость изучали в центральной части (по высоте) дисков.

Рентгеноструктурный и рентгенофазовый анализ проводили на дифрактометре Shimadzu XRD-6000 (с монохроматором) с использованием $\mathrm{Cu} \mathrm{K}_{\alpha}$ излучения в интервале углов $2 \theta=40-100^{\circ}$ с шагом 0,02 градуса и временем экспозиции в точке 1 с (с вращением). Расшифровку рентгенограмм - идентификацию и определение количественного содержания фаз - осуществляли с помощью программного обеспечения PowderCell, картотеки PDF (Powder Diffraction File). Анализ параметров кристаллического строения, микродеформации кристаллической решетки $\Delta d / d$ и размеров областей когерентного рассеяния проводили методом аппроксимации [14]. При прецизионном измерении параметров решетки использовали экстраполяционную функцию $f(\theta)=1 / 2\left(\cos ^{2} \theta / \sin \theta+\cos ^{2} \theta / \theta\right)$ [15]. Концентрацию де- 
фектов упаковки $(\alpha)$ рассчитывали по изменению положения рентгеновских максимумов по соотношению [14]:

$$
\Delta\left(2 \theta_{200}-2 \theta_{111}\right)=\frac{-90 \sqrt{3} \alpha}{\pi^{2}}\left(\frac{\operatorname{tg} \theta_{200}}{2}+\frac{\operatorname{tg} \theta_{111}}{2}\right),
$$

где $\Delta\left(2 \theta_{200}-2 \theta_{111}\right)$ представляет собой разность между значениями $\left(2 \theta_{200}-2 \theta_{111}\right)$ для деформированного и недеформированного состояний. Положения максимумов в недеформированном состоянии определяли для деформированных и закаленных образцов.

Микротвердость (Н $\mu)$ образцов до и после деформации измеряли по методу Виккерса при комнатной температуре с использованием микротвердомера Duramin-5 с нагрузкой на индентор 200 г. Из-за особенностей деформации на наковальнях Бриджмена $[1,3]$ изучали распределение микротвердости по диаметру образца, а также определяли среднее значение микротвердости на середине радиуса диска.

\section{3. Результаты и их обсуждение}

На Рис. 1 представлены рентгенограммы для монокристаллов стали Fe-28Mn-2,7Al-1,3C, подвергнутых КВД при разных температурах. Параметры структуры, определённые из данных рентгеновской дифракции, приведены в Табл. 1. Анализ рентгенограмм (Рис. 1) показал, что КВД приводит к снижению интенсивности рентгеновских линий и их уширению. Значения областей когерентного рассеяния слабо зависят от температуры деформации и после одного оборота КВД составляют $25 \div 35$ нм, а затем уменьшаются с деформацией до $12 \div 16$ нм (Табл. 1). Микродеформация кристаллической решетки после одного оборота КВД имеет высокие значения $\Delta d / d=0,9 \div 5,5 \times 10^{-3}$, но с увеличением степени деформации (числа оборотов) немного снижается (Табл. 1). Эти параметры свидетельствуют об измельчении структуры и росте внутренних напряжений.

Независимо от температуры деформации, сталь сохраняет аустенитную структуру - на рентгенограммах наблюдаются отражения только от аустенита. Соотношение интенсивности рентгеновских максимумов указывает на формирование текстуры (111) в плоскости наковален. Это свидетельствует о том, что кручение под давлением приводит к формированию разориентированной (не монокристаллической) структуры в стали, но исходная кристаллографическая ориентировка является, по-прежнему, преобладающей.

При холодной деформации $($ КВД 23 параметр решетки стали Fe-28Mn-2,7Al-1,3C имеет значения $a=3,652-3,653 \AA$ А. Параметр решетки, рассчитанный на основе элементного состава матрицы с учетом элементов замещения и внедрения по формуле $a_{\gamma}$ [нм] = $0,3577[\mathrm{Hм}]+0,00010[$ нм/ат. $\%] \times \mathrm{Mn}+0,00028 \times \mathrm{Al}+$ $0,00065 \times \mathrm{C}[16]$, имеет близкое значение и составляет $a=3,654 \AA$ А. Это подтверждает, что в процессе кручения под давлением при комнатной температуре не происходит выделения вторичных фаз, и весь углерод находится в твердом растворе (внедрения).

В то же время повышение температуры деформации и увеличение числа оборотов при КВД 200 и КВД 400 приво- дит к уменьшению параметра решетки, обусловленному выходом атомов углерода из твердого раствора (Табл. 1). После КВД ${ }_{400}$ на 5 оборотов изменение параметра решетки по отношению к исходному состоянию составляет $\Delta a=0,015 \AA$, что в соответствии с [16] обеспечивает обеднение аустенита по углероду примерно на 2,3 ат.\% (0,55 мас. \%). Согласно данным, приведенных в работе [17], при теплом кручении под давлением при $573 \mathrm{~K}$ TWIP-стали Fe-18Mn-0,75C-1,7Al-0,5Si происходит выделение цементита и карбидов $\mathrm{M}_{23} \mathrm{C}_{6}$. Поскольку эта сталь имеет близкую систему легирования и деформирована при близких условиях, то можно предположить, что в исследуемой стали Fe-28Mn-2,7Al-1,3C также мо-

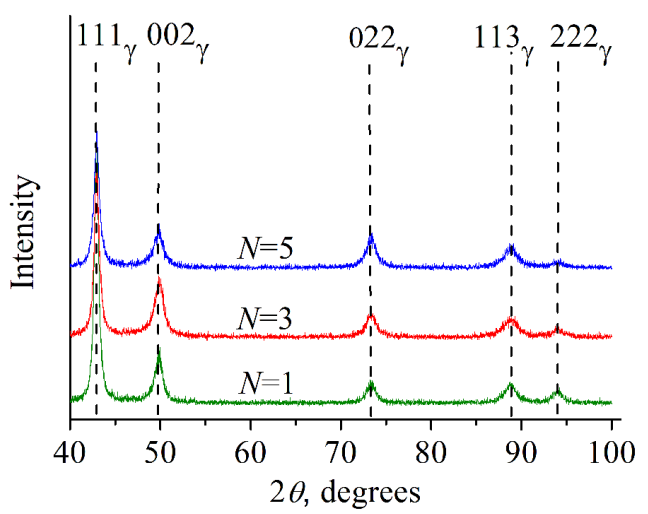

a

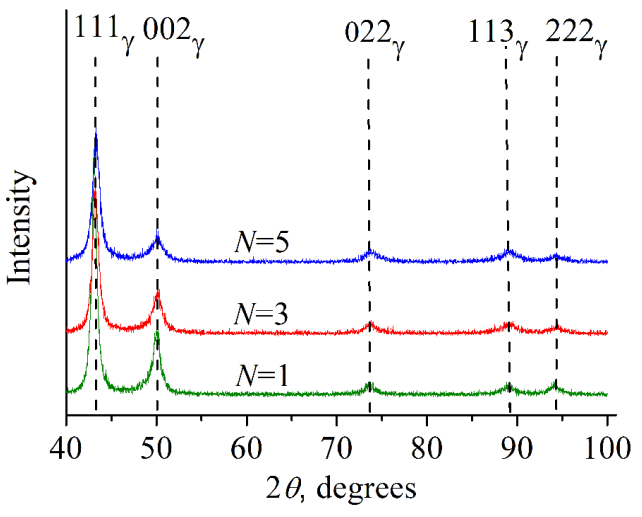

b

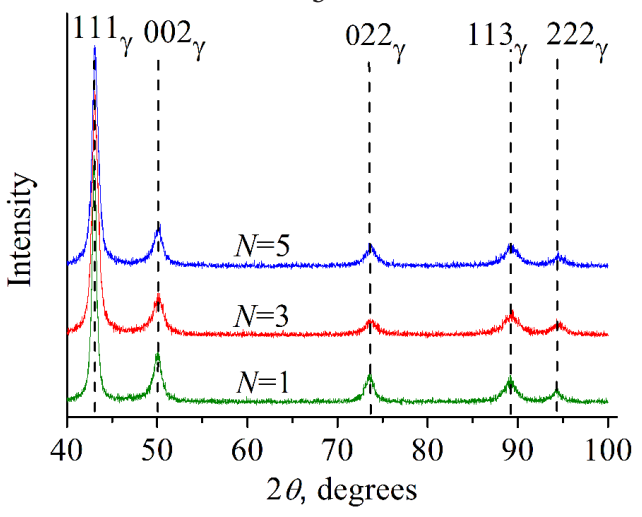

c

Рис. 1. Рентгенограммы стали Fe-28Mn-2,7Al-1,3C после КВД при $T=23^{\circ} \mathrm{C}(\mathrm{a}), T=200^{\circ} \mathrm{C}(\mathrm{b}), T=400^{\circ} \mathrm{C}$ (c) в зависимости от числа оборотов.

Fig. 1. The X-ray diffraction of Fe-28Mn-2.7Al-1.3C steel processed by $\mathrm{HPT}$ at $T=23^{\circ} \mathrm{C}(\mathrm{a}), T=200^{\circ} \mathrm{C}$ (b), $T=400^{\circ} \mathrm{C}$ (c) depending on the number of revolutions. 
Табл. 1. Микротвердость и параметры структуры (параметр кристаллической решетки $a$, размеры областей когерентного рассеяния (ОКР), микродеформация кристаллической решетки $\Delta d / d$, концентрация дефектов упаковки (КДУ)), определенные рентгеновским методом для монокристаллов стали Fe-28Mn-2,7 Al-1,3С после КВД.

Table 1. The microhardness and structural parameters (lattice parameter $a$, sizes of the coherent-scattering regions (CSR), microstrain of the crystal lattice $\Delta d / d$, stacking fault probability (SFP)) determined by the X-ray method in HPT-processed Fe-28Mn-2.7Al-1.3C steel.

\begin{tabular}{|c|c|c|c|c|c|c|c|c|c|c|}
\hline \multirow{3}{*}{$N$} & \multirow{2}{*}{\multicolumn{3}{|c|}{$\begin{array}{c}2 \theta, \text { град / } 2 \theta, \text { degrees } \\
\text { FWHM }\end{array}$}} & \multirow{3}{*}{$\frac{I_{111 \gamma}}{I_{200 \gamma}}$} & \multirow{3}{*}{$a, \AA$} & \multirow{3}{*}{$\begin{array}{l}C_{\mathrm{C}}, \text { мac. } \% \\
C_{\mathrm{C}}, \text { wt. } \%\end{array}$} & \multirow{3}{*}{$\begin{array}{l}\text { OKР, нм } \\
\text { CSR, nm }\end{array}$} & \multirow{3}{*}{$\Delta d / d \times 10^{-3}$} & \multirow{3}{*}{$\begin{array}{l}\text { КДУ, \% } \\
\text { SFP, \% }\end{array}$} & \multirow{3}{*}{$\begin{array}{l}\mathrm{H} \mu, \text { ГПа } \\
\mathrm{H} \mu, \mathrm{GPa}\end{array}$} \\
\hline & & & & & & & & & & \\
\hline & $111 \gamma$ & $200 \gamma$ & $220 \gamma$ & & & & & & & \\
\hline \multicolumn{11}{|c|}{$T_{\text {Квд }}=23^{\circ} \mathrm{C} / T_{\mathrm{HPT}}=23^{\circ} \mathrm{C}$} \\
\hline \multirow{2}{*}{1} & 42.93 & 49.83 & 73.35 & \multirow{2}{*}{5.1} & \multirow{2}{*}{3.653} & \multirow{2}{*}{1.3} & \multirow{2}{*}{27} & \multirow{2}{*}{0.9} & \multirow{2}{*}{2.9} & \multirow{2}{*}{4.9} \\
\hline & 0.651 & 1.098 & 1.323 & & & & & & & \\
\hline \multirow{2}{*}{3} & 42.96 & 49.87 & 73.37 & \multirow{2}{*}{2.9} & \multirow{2}{*}{3.652} & \multirow{2}{*}{1.3} & \multirow{2}{*}{22} & \multirow{2}{*}{0.6} & \multirow{2}{*}{3.0} & \multirow{2}{*}{6.1} \\
\hline & 0.738 & 1.147 & 1.465 & & & & & & & \\
\hline \multirow{2}{*}{5} & 42.96 & 49.79 & 73.36 & \multirow{2}{*}{3.4} & \multirow{2}{*}{3.653} & \multirow{2}{*}{1.3} & \multirow{2}{*}{14} & \multirow{2}{*}{0.2} & 42 & 65 \\
\hline & 0.813 & 1.287 & 1.502 & & & & & & 4.2 & 0.0 \\
\hline & & & & $T_{\text {Квд }}$ & $\mathrm{C} / \mathrm{T}_{1}$ & $=200^{\circ} \mathrm{C}$ & & & & \\
\hline 1 & 43.11 & 50.01 & 73.64 & 38 & 3.648 & 11 & 35 & 5.5 & 34 & 71 \\
\hline 1 & 0.739 & 1.084 & 1.618 & 3.8 & 3.048 & 1.1 & 30 & & & \\
\hline 3 & 43.24 & 50.08 & 73.72 & 35 & 3647 & 1.1 & 16 & 48 & 49 & 73 \\
\hline & 0.739 & 1.277 & 1.594 & & & & & & & \\
\hline 5 & 43.31 & 50.11 & 73.85 & 4.9 & 3646 & 10 & 12 & 4.4 & 61 & 79 \\
\hline 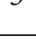 & 1.041 & 1.603 & 1.982 & 10. & & & 12 & & & 1.0 \\
\hline & & & & $T_{\text {квд }}$ & $\mathrm{C} / \mathrm{T}_{1}$ & $=400^{\circ} \mathrm{C}$ & & & & \\
\hline 1 & 43.04 & 50.03 & 73.54 & 4.8 & 3.644 & 0.8 & 25 & 3.3 & 1.7 & 6.1 \\
\hline & 0.643 & 1.111 & 1.245 & & & & & & & \\
\hline 3 & 43.12 & 50.11 & 73.69 & 5.9 & 3.639 & 0.8 & 20 & 2.9 & 19 & 7.1 \\
\hline & 0.878 & 1.324 & 1.699 & 3.9 & 3.639 & & & & & \\
\hline 5 & 43.13 & 50.10 & 73.69 & 56 & 3.638 & 0.8 & 13 & 21 & 22 & 7.5 \\
\hline 3 & 0.881 & 1.147 & 1.621 & & & & 10 & & 2.2 & \\
\hline
\end{tabular}

жет происходить образование карбидов с объемной долей менее 5\%, которые не выявляются методами рентгеновской дифракции. Данные об оценке концентрации атомов внедрения (углерода) $\left(C_{\mathrm{C}}\right)$, полученные на основе изменения параметра решетки с использованием коэффициента $\Delta a=0.00065$ [нм/ат. \%] для углерода [16], в зависимости от обработки приведены в Табл. 1. Несмотря на обезуглероживание, $C_{\text {С }}$ в твердом растворе остается достаточно высокой и обеспечивает высокий уровень твердорастворного упрочнения исследуемой стали и стабильную аустенитную структуру.

В исходном состоянии микротвердость монокристаллов стали составляла 2,5 ГПа. КВД приводит к ее росту с увеличением степени деформации (Рис. 2; Табл. 1). При КВД в 2 раза, при $N=3-5$ микротвердость достигает значений $6,1-6,5$ ГПа и слабо изменяется с увеличением числа оборотов (Табл. 1; Рис. 2). Как видно из Рис. 2а, провалов микротвердости, характерных для деформации методом КВД [3], в центре диска не наблюдается - распределение Н $\mu$ вдоль диаметра диска после КВД имеет квазиоднородный характер. Теплое КВД сопровождается увеличением микротвердости на 1,0-2,2 ГПа по сравнению с КВД при комнатной температуре (Рис. 2b, с; Табл. 1), и самые высокие значения соответствуют деформации при $200^{\circ} \mathrm{C}$. Как видно из Рис. 2b, с, после теплого КВД наблюдается неоднородность в распределение Н $\mu$ вдоль диаметра диска, которая усиливается с повышением температуры деформации.

Деформация сжатием (сжатие, предшествующее процессу КВД) приводит к деформации и фрагментации структуры монокристаллов стали Fe-28Mn-2,7Al-1,3C. Это происходит, как было показано ранее в работе [4], за счет развития механического двойникования и образования полос локализованной пластической деформации. Формирование сетки двойниковых границ уже в процессе сжатия (приложения давления перед кручением) способствует накоплению дислокаций, и такое субструктурное упрочнение вместе с эффектом твердорастворного упрочнения обусловливают высокие значения микротвердости стали после КВД при комнатной температуре и однородное распределение микротвердости по диаметру деформированных дисков. Оценка концентрации дефектов упаковки, проведенная на основе данных о смещении рентгеновских линий аустенита при деформации, подтверждает данные работы [4] о склонности исследуемой стали к развитию двойникования и увеличении его активности с ростом степени деформации при КВД 23 (Табл. 1). Повышение температуры деформации является фактором, способствующим снижению активности механического двойникования [18]. С другой стороны, обезуглероживание способствует уменьшению энергии дефекта упаковки высокомарганцевого аустенита [8], то есть, напротив, 


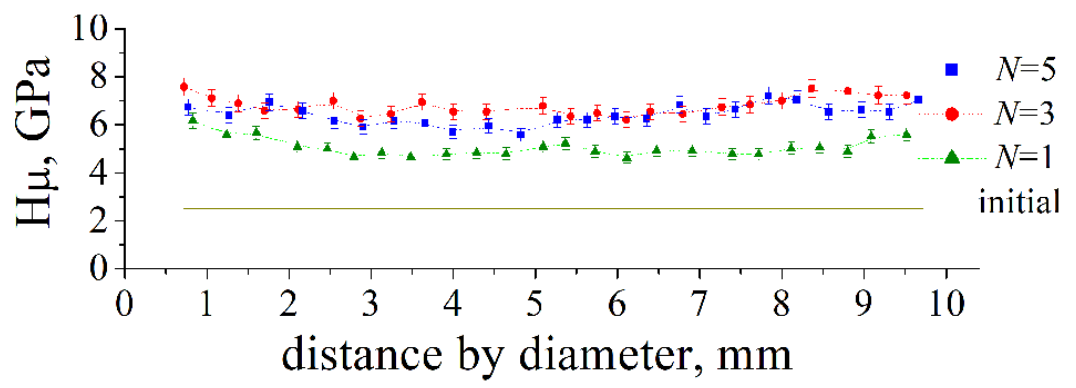

a

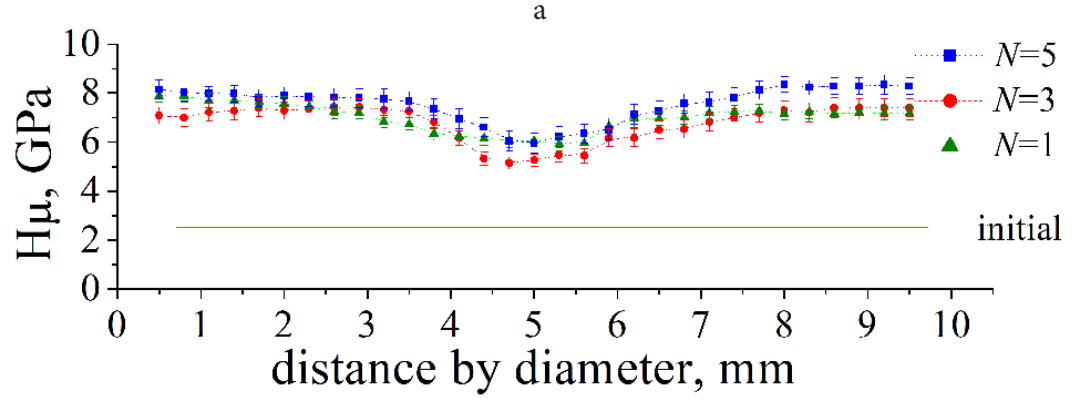

b

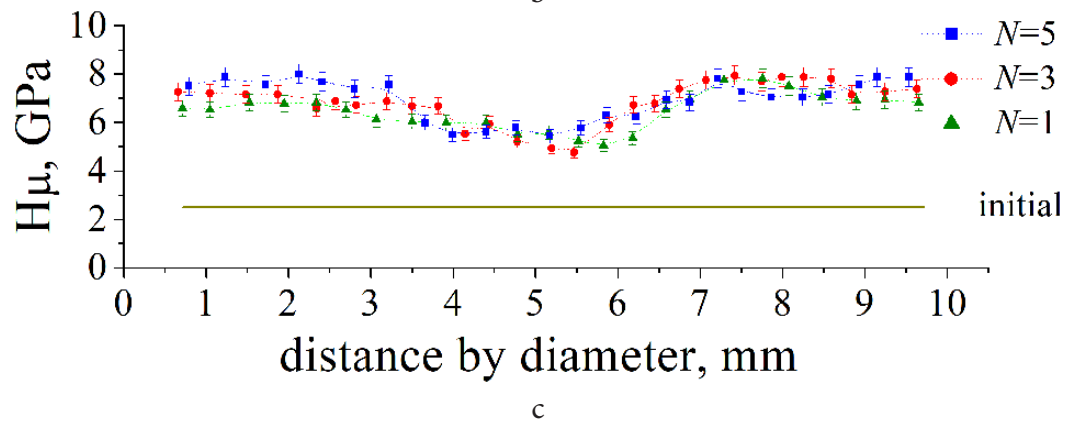

Рис. 2. Распределение микротвердости по диаметру дисков из стали $\mathrm{Fe}-28 \mathrm{Mn}-2,7 \mathrm{Al}-1,3 \mathrm{C}$ после КВД при $T=23^{\circ} \mathrm{C}(\mathrm{a}), T=200^{\circ} \mathrm{C}(\mathrm{b})$, $T=400^{\circ} \mathrm{C}(\mathrm{c})$ в зависимости от числа оборотов.

Fig. 2. The microhardness distribution along the diameter of the disks from $\mathrm{Fe}-28 \mathrm{Mn}-2.7 \mathrm{Al}-1.3 \mathrm{C}$ steel after the $\mathrm{HPT}$ at $T=23^{\circ} \mathrm{C}(\mathrm{a})$, $T=200^{\circ} \mathrm{C}(\mathrm{b}), T=400^{\circ} \mathrm{C}$ (c) depending on the number of revolutions.

будет стимулировать развитие двойникования. Второй фактор преобладает при деформации КВД $200-$ наблюдается повышение концентрации дефектов упаковки по сравнению с комнатной температурой. А первый фактор превалирует при КВД туры деформации до $400^{\circ} \mathrm{C}$ сопровождается снижением концентрации дефектов упаковки (Табл. 1).

Таким образом, при исследуемых температурах деформации методом КВД несколько факторов упрочнения могут определять наблюдаемые различия в микротвердости: с ростом температуры снижается уровень твердорастворного упрочнения из-за частичного обезуглероживания аустенита (разупрочнение), происходит дисперсионное твердение (упрочнение), повышается (при $200^{\circ} \mathrm{C}$, упрочнение) или понижается (при $400^{\circ} \mathrm{C}$, разупрочнение) вероятность развития механического двойникования. Наблюдаемые различия в распределении микротвердости по диаметру диска вызвано, вероятно, различием в механизме деформации и фрагментации структуры стали и процессов релаксации при изменении температуры деформации.

\section{4. Заключение}

Методами рентгеноструктурного и рентгенофазового анализа изучены параметры структуры и фазовый состав монокристаллов высокомарганцевой аустенитной стали Fe-28Mn-2,7Al-1.3C (мас. \%), подвергнутых холодному (при $T=23^{\circ} \mathrm{C}$ ) и теплому (при $T=200$ и $400^{\circ} \mathrm{C}$ ) кручению в наковальнях Бриджмена.

Независимо от температуры деформации, сдвиг под давлением приводит к деформации монокристаллов и формированию разориентированной аустенитной структуры с преимущественной ориентацией плоскостей $\{111\}$ в плоскости наковален. Увеличение степени деформации (числа оборотов при кручении) способствует уменьшению размеров областей когерентного рассеяния и микродеформации кристаллической решетки и вызывает рост концентрации дефектов упаковки.

Независимо от температуры деформации и числа оборотов при КВД, сталь сохраняет аустенитную структуру с параметром решетки, свидетельствующем о высо- 
ком уровне твердорастворного упрочнения. Увеличение температуры деформации способствует снижению параметра кристаллической решетки аустенита, что указывает на частичное обезуглероживание аустенита. При этом на рентгенограммах наблюдаются линии с межплоскостными расстояниями, соответствующими только аустенитной фазе.

В результате деформации микротвердость стали увеличивается, и ее величина существенным образом зависит от температуры кручения. При холодной деформации кручением под высоким давлением распределение микротвердости по диаметру диска является квазиоднородным и слабо изменяется с ростом числа оборотов. Увеличение температуры деформации приводит к неоднородному распределению микротвердости по диаметру диска - в центре значения ниже, чем у края диска.

Благодарность/Acknowledgements. Авторь cmamьи выражают благодарность профессору Ю.И. Чумлякову за предоставленные монокристалль стали и к.ф.-м.н. Тукеевой М.С. за помощь в проведении исследований методом рентгеноструктурного анализа. Работа выполнена при поддержке Российского фонда фундаментальных исследований (проект № 16-38-00232-мол_а). Исследования выполнены с использованием оборудования Томского материаловедческого иентра коллективного пользования и ЦКП «Нанотех» ИФПМ СО РАН./Authors of the article express their gratitude to Professor Yu. I. Chumlyakov for single crystals of steel and to Ph.D. Tukeeva M.S. for assistance in conducting $X$-ray diffraction analysis. The work is supported by Russian Foundation for Basic Researches (project No 16-38-00232-mol_a). Research were performed using the equipment of Tomsk materials center of collective use and Nanotech Center of the ISPMS SB RAS.

\section{Литература/Reference}

1. R.Z. Valiev, I.V. Alexandrov. Bulk nanostructured metallic materials. Moskow, IKZ «Akademkniga» (2007) 398 p. (in Russian) [Валиев Р.3., Александров И.В. Объемные наноструктурные металлические материалы: получение, структура, свойства. Москва, ИКЦ «Академкнига» (2007) 398 с.]

2. N.I. Noskova, R.R. Mulyukov. Submicrocrystalline and nanocrystalline metals and alloys. Yekaterinburg, UrO RAN (2003) 279 p. (in Russian) [Н.И. Носкова, P. P. Мулюков. Субмикрокристаллические и нанокристаллические металлы и сплавы. Екатеринбург, УрО
PAH (2003) 279 c.]

3. A.P. Zhilyaev, T.G. Langdon. Prog. Mater. Sci. 53, 893 (2008). DOI: 10.1016/j.jmrt.2014.06.008

4. E. G. Astafurova, M.S. Tukeeva, V.A. Moskvina, N.K. Galchenko, I. A. Bataev, V.A. Bataev. Letters on materials 4(4), 269 (2014). DOI:10.22226/2410-3535-2014-4-269-272

5. E. G. Astafurova, M.S. Tukeeva, G.G. Zakharova, E. V. Melnikov, H. J. Maier. Mater. Char. 62, 588 (2011). DOI: 10.1016/j.matchar.2011.04.010

6. E.G. Astafurova, M.S. Tukeeva, G.G. Maier, E. V. Melnikov, H.J. Maier. Mater. Sci.Eng. A604, 166 (2014). DOI: 10.1016/j.msea.2014.03.029

7. V.A. Shabashov, L.G. Korshunov, V.V. Sagaradze et al. Phys.Met. Metall. 114, 681 (2013). DOI: 10.1134/S0031918X13080097

8. S. Allain, J.-P. Chateau, O. Bouaziz, S. Migot, N. Guelton. Mater. Sci. Eng. A 387-389, 158 (2004). DOI: 10.1016/j.msea.2004.01.059

9. A.V. Makarov, S.N. Luchko, V.A. Shabashov et. al. Phys. Met. Metallogr. 118(1), 55 (2017). (in Russian) [А. В. Макаров, С. Н. Лучко, В. А. Шабашов и др. ФММ. 118(1), 55 (2017).] DOI: 10.1134/S0031918X17010045

10. F. Y. Dong, P. Zhang, J. C. Pang et al. Scripta Mater. 96, 5 (2014). DOI: 10.1016/j.scriptamat.2014.09.016

11. O. Bouaziz, S. Allain, C.P. Scott, D. Barbier. Current Opinion in Solid State and Mater. Sci. 15(4), 141 (2011). DOI: 10.1016/j.cossms.2011.04.002

12. B. H. Park, H. Y. Um, J. G. Kim, H. Y. Jeong et al. Met. Mater. Int. 22(6), 1003 (2016). DOI: 10.1007/s12540-016-6279-Z

13. M. S. Matoso, R. B. Figueiredo, M. Kawasaki, D. B. Santos, T.G. Langdon. Scripta Mater. 67, 649 (2012). DOI: 10.1016/j.scriptamat.2012.07.019.

14. S.S. Gorelic, Yu. A. Skakov, L.N. Rastorguev. X-ray diffraction and electron-optical analysis. Moscow, MISIS (2002) 360 p. (in Russian) [Горелик С. С., Скаков Ю. А., Расторгуев Л.Н. Рентгенографический и электроннооптический анализ. Москва, МИСИС (2002) 431 с.]

15. A. Taylor.X-ray metallography. Moscow, Metallurgy (1965) 663 р. [Тейлор А. Рентгеновская металлография. Москва, Металлургия (1965) 663 с.]

16. S.-J. Lee, Y.-K. Lee. Scripta Mater. 52(10), 973 (2005). DOI: 10.1016/j.scriptamat.2005.01.028

17. X.H. An, Q.Y. Lin, G. Sha, M.X. Huang, S.P. Ringer, Y.T. Zhu, X.Z. Liao. Acta Mater. 109(1), 300 (2016). DOI: $10.1016 /$ j.actamat.2016.02.045

18. J. W. Christian, S. Mahajan. Progr. in Mater. Sci. 39(1-2), 1 (1995). DOI: 10.1016/0079-6425(94)00007-7 